\title{
Synopsis: Geography of public service delivery in rural Ethiopia *
}

\author{
Gashaw T. Abate, Mekdim Dereje, Kalle Hirvonen, and Bart Minten
}

\begin{abstract}
Geography has been shown to be an important determinant of economic development. Remote areas tend to be poorer due to higher transaction costs for trade or inhospitable environments. In this study, we show that remote areas in rural Ethiopia are also disadvantaged in their access to public service delivery. Relying on large household surveys, we assessed the association between exposure to agriculture and health extension and two measures of remoteness: (1) the distance of service centers to district capitals; and (2) the distance of households to service centers (i.e., the last mile). We found that villages located farther away from district capitals were less likely to receive agricultural extension services than other villages. In contrast, exposure to health extension services did not vary across more and less connected villages. This difference between the two sectors could be due to the fact that more remote villages tend to have fewer agriculture extension workers who also put in fewer hours into their work than their peers. We did not find similar evidence in the health sector. Finally, for both sectors, we found that the last mile matters: more remote households within villages were less likely to receive both types of extension services.
\end{abstract}

\section{Introduction}

Previous literature has quantified a sizable remoteness penalty along several welfare dimensions, largely attributing this to economic disadvantages and higher trade barriers. We contribute to this literature by studying how geography shapes public service delivery in rural Ethiopia (for more details, see Abate et al. 2019). A novel feature of our study is that we considered two types of remoteness. First, we assessed how public service delivery differs between remote and less remote villages within the same administrative area. Second, we studied how the remoteness of households from the service center is associated with differential access to public services in rural areas in Ethiopia. This distinction is important as it leads to different policy implications to ensure the inclusiveness of remote areas or households in service provision. Moreover, our assessment 
contrasted two key sectors, agriculture and health, in which public service provision plays a vital role.

\section{Context}

Ethiopia has seen successful human and agricultural development in the last decade as measured by changes in a number of indicators in the social sectors and in agriculture. In the agricultural sector, increasing adoption of improved modern inputs has led to considerable yield increases, estimated at approximately 5 percent annually over the last decade (Bachewe et al. 2018). In the health sector, indicators for maternal and child health improved significantly. While the country has invested heavily in the construction of roads in the last decade, remoteness is still a dominant characteristic of rural life. Schmidt et al. (2018) estimated that in 2015 more than 20 percent of Ethiopians were residing more than 5 hours travel time from a city of at least 50,000 people.

In agriculture, the government has made sizable investments to set up a large-scale public agricultural extension system. The effort has focused on the provision of advisory and training services through a public extension structure. The plan was to assign at least three Development Agents (DAs), specializing in crop production, livestock, and natural resources, respectively, in each kebele. The DAs are mandated to carry out agricultural extension services. Each kebele is expected to build a Farmer Training Center where farmers have access to participatory demonstrations for improved technologies and new farming systems. Berhane et al. (2018) report that Ethiopia has one DA per 230 farmers, one of the highest extension agent-to-farmer ratios in the world.

In the health sector, an extension program was launched in 2002/03 by the Ethiopian government, and now covers nearly all woredas of the country. The program focuses on hygiene and environmental sanitation, disease prevention and control, and family health services. The health extension workers (HEWs) play a key role in implementing the health extension program. There is one health post per kebele and typically two HEWs are assigned to each health post. Together they are expected to reach approximately 5,000 individuals. The main tasks of the HEWs include the provision of basic health services and the promotion of health-related messages.

\section{Data and methodology}

We used data from two large household surveys to assess the role of remoteness on the delivery of agricultural and health extension services. To analyze service delivery in the agriculture sector, we used data from a survey of 2,422 farm households administered in 30 woredas and 346 kebeles in Amhara; Oromia; Southern Nations, Nationalities, and Peoples' (SNNP); and Tigray regions. To assess the role of geography in health extension, we used data from a survey administered in March 2017. For this survey, a sample of 2,635 households with children less than 24 months of age was drawn from 88 woredas and 264 kebeles in Amhara; Oromia; SNNP; and Tigray regions in which the Productive Safety Net Program of Ethiopia operates.

We used regression techniques to assess the relationship between service delivery and remoteness in rural Ethiopia. This involved modelling a household's exposure to extension services as a function of two measures of remoteness: 1) the community's distance to the woreda capital; and 2) the household's distance to the kebele center. Because households located in more remote localities are likely to differ from less remote households in several ways, we included household level controls in the regression models. 


\section{Findings}

We document strong correlations between exposure to agriculture extension and advice along both distance gradients even after controlling for differences in various household characteristics. For example, relative to farm households in the least-remote kebeles, households located in the farthest kebeles had a 5-percentage point lower likelihood of a visit by a DA. Given that only 30 percent of our sample farmers were visited by the DA, this translates into a 17 percent drop in the likelihood that a DA visited households in the most remote locations. Relative remoteness within one's kebele seemed to matter even more. Farm households residing farthest from the Farmer Training Center in their kebele had a 37 percent (11 percentage points) lower probability of a plot level visit by a DA compared to the least remote households. We also found that remote households were less likely to receive advice on fundamental inputs (fertilizer and seed) and crop specific practices. Together, these results imply that doubly remote households, i.e., those located in remote kebeles and far away from the Farmer Training Center in their kebele, were least likely to receive extension services.

In contrast to agricultural extension, we found that a household's exposure to health extension was not associated with distance to the woreda capital. However, we did document strong associations regarding exposure to health extension and a household's distance to the health post. Compared to least remote households, households located farthest away from the health post were 7 percentage points less likely to even know a HEW in their kebele. Considering that 79 percent of the households knew at least one HEW working in their kebele, this translates into a 11 percent lower likelihood of knowing a HEW. A similar story emerged when we assessed the likelihood of having met a HEW. For example, HEWs were less likely to visit homes that are located far from the health post. Moreover, pregnant mothers located far from the health post were 5 percentage points (17 percent) less likely to receive a visit from a HEW as compared to those located close to the health post.

These results put forward two interesting stylized facts. First, the last mile matters: more remote households within a kebele are considerably less likely to receive both types of extension services; agriculture and health. Second, exposure to agriculture extension declines as we move from more connected kebeles to kebeles located far from the woreda capital. But interestingly, we do not document a negative gradient when it comes to exposure to health extension.

\section{Figure 1: Number of extension agents in kebele and distance to woreda capital}

a) Agriculture Extension

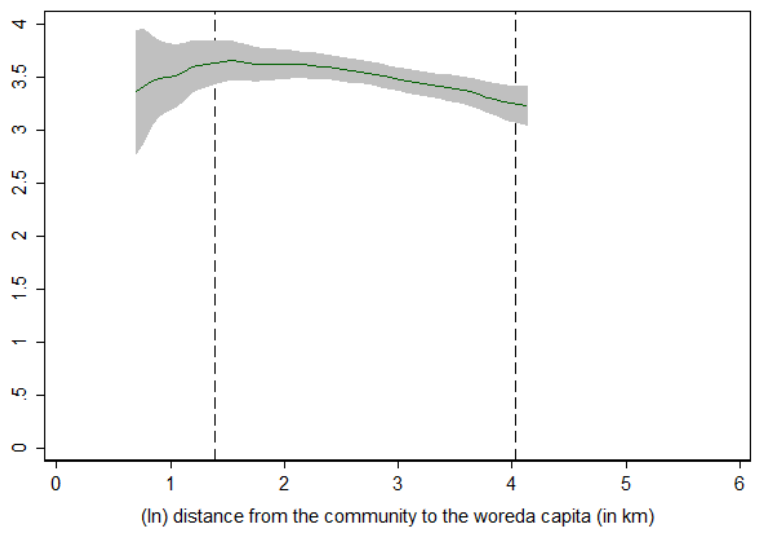

b) Health Extension

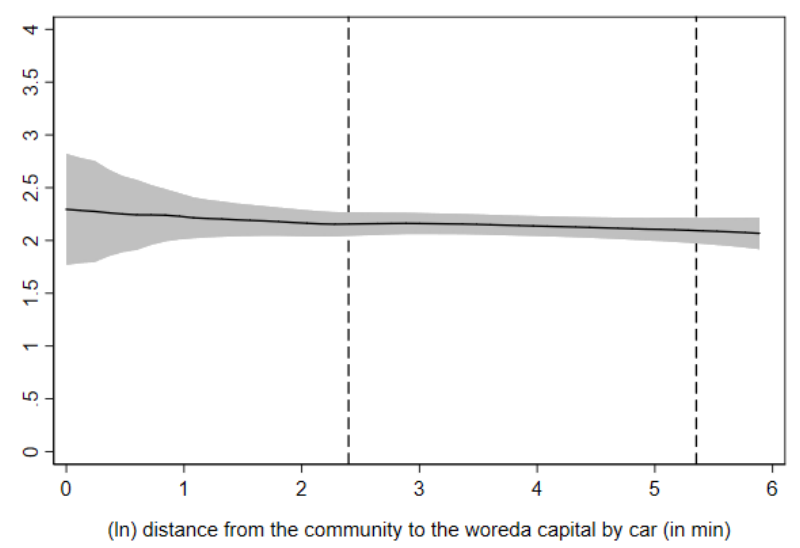

Note: Local polynomial regression. The vertical axis in both graphs measures the number of extension workers operating in the kebele. The area between the dashed lines indicates the $90 \%$ confidence interval of the distance distribution (between the kebele center and woreda capital). 
We explored some potential reasons for the difference between the two sectors. We ran a series of locally weighted polynomial regressions in which we regress various extension worker characteristics on the distance from the kebele to the woreda capital. Starting from Figure 1, we see how the number of DAs declines as we move to more remote kebeles, but the same is not true for HEWs. Figure 2 shows that DAs in more remote localities work less hours per week. However, we do not observe a similar gradient for HEWs - if anything, HEWs in more remote localities report working slightly more hours per month than their peers located closer to the woreda capital.

\section{Figure 2: Reported working hours and distance to woreda capital}

a) Agriculture Extension (hours/week)

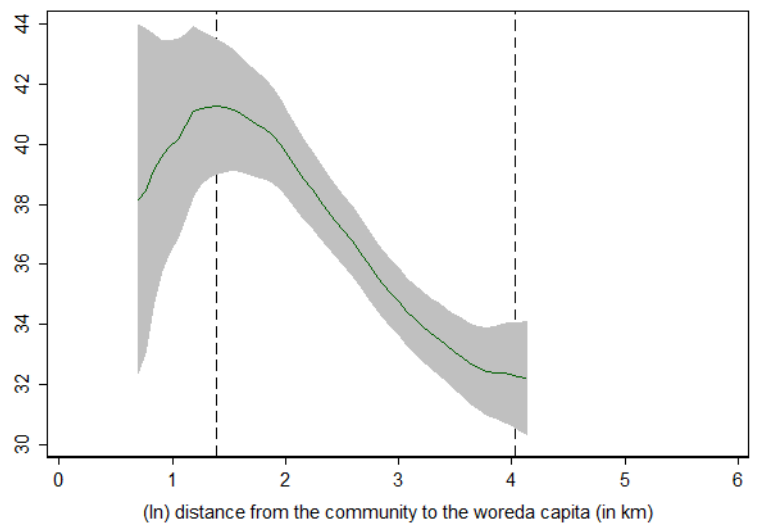

b) Health Extension (hours/month)

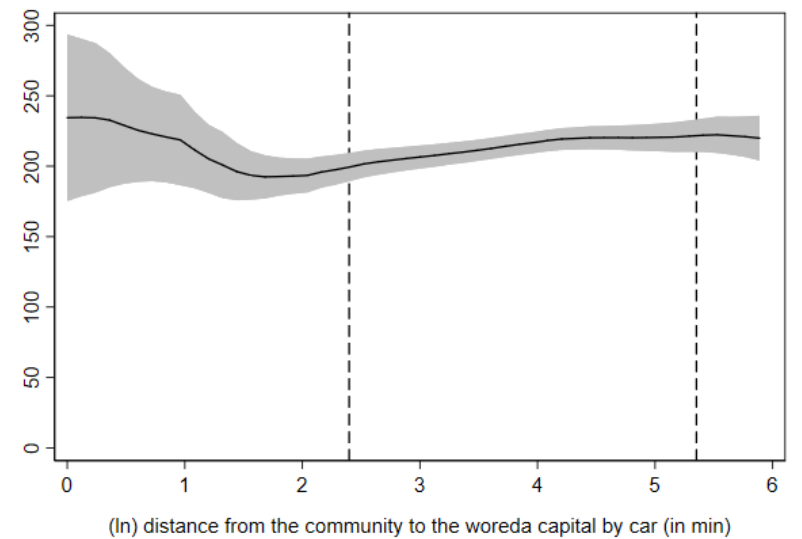

Note: Local polynomial regression. The vertical axis in graph a) measures the number of typical working hours per week reported by the agriculture extension worker. In graph b) the vertical axis measures the number of typical working hours per month reported by the HEW. The area between the dashed lines indicates the $90 \%$ confidence interval of the distance distribution (between the kebele center and woreda capital).

Together, these results indicate that the total manpower - that is, the number of extension workers and their effort - in agricultural extension is lower in more remote localities compared to those located closer to the woreda capital. This alone could explain the finding that farm households in more remote kebeles are less likely to receive agriculture extension services.

\section{Policy recommendations}

To ensure better inclusiveness of remote rural residents in their access to social services, a number of actions could be envisaged. A denser system of outreach could be aimed to cover especially the last mile. Extension agents from outside areas are often reluctant to settle in more remote places because living conditions are often worse in these areas and the agents have no additional incentives to do so. Offering better financial incentives to public agents posted in more remote areas could be one policy option to reverse this. However, non-financial incentives may also be highly effective. For example, Ashraf et al. (2019) show how emphasizing career opportunities within the civil service sector during the recruitment process in Zambia led to a more qualified pool of rural health workers who also performed better on their job. Exploring these policy options in the rural Ethiopian context forms an important path for future research. 


\section{References}

Abate, G.T., M. Dereje, K. Hirvonen and B. Minten (2019). Geography of public service delivery in rural Ethiopia. IFPRIEthiopia Strategy Support Program Working Paper 133. Addis Ababa: International Food Policy Research Institute. http://ebrary.ifpri.org/cdm/ref/collection/p15738coll2/id/133338

Ashraf, N., O. Bandiera and S. Lee. 2019. Losing prosociality in the quest for talent? Sorting, selection, and productivity in the delivery of public services. Unpublished manuscript. London: London School of Economics.

Bachewe, F., G. Berhane, B. Minten, and A.S. Taffesse. 2018. "Agricultural transformation in Africa? Assessing the evidence in Ethiopia." World Development 105: 286-298.

Berhane, G., C. Ragasa, G.T. Abate, and T.W. Assefa. 2018. The state of agricultural extension services in Ethiopia and their contribution to agricultural productivity. IFPRI-Ethiopia Strategy Support Program Working Paper 118. Addis Ababa: International Food Policy Research Institute.

Schmidt, E., P. Dorosh, M.K. Jemal, and J. Smart. 2018. Ethiopia's spatial and structural transformation: Public policy and drivers of change. IFPRI-Ethiopia Strategy Support Program Discussion Paper 119. Washington, DC: International Food Policy Research Institute.

\section{ABOUT THE AUTHORS}

Gashaw T. Abate is a Research Coordinator in the Markets, Trade, and Institutions Division of the International Food Policy Research Institute (IFPRI), based in Addis Ababa. Mekdim Dereje is a PhD student in the Center for Development Research (ZEF), University of Bonn, Germany. Kalle Hirvonen is a Senior Research Fellow in IFPRI's Ethiopia Strategy Support Program (ESSP) in the Development Strategy and Governance Division (DSGD) of IFPRI, based in Addis Ababa.

Bart Minten is Program Leader of ESSP and a Senior Research Fellow in DSGD of IFPRI, based in Addis Ababa.

INTERNATIONAL FOOD POLICY RESEARCH INSTITUTE

1201 Eye St, NW | Washington, DC 20005 USA

T. +1-202-862-5600 | F. +1-202-862-5606

Email: ifpri@cgiar.org | www.ifpri.org | www.ifpri.info

\section{IFPRI-ESSP ADDIS ABABA}

P.O. Box 5689, Addis Ababa, Ethiopia

T. +251-11-617-2000 | F. +251-11-667-6923

Email: ifpri-essp@cgiar.org | http://essp.ifpri.info
POLICY STUDIES INSTITUTE

P.O. Box 2479, Addis Ababa, Ethiopia

T. +251.11-550-6066; +251-11-553-8633 | F. +251-11-550-5588

http://psi.gov.et/

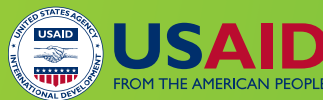

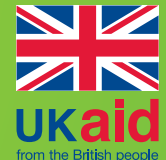

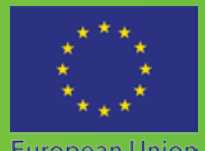

The Ethiopia Strategy Support Program (ESSP) is managed by the International Food Policy Research Institute (IFPRI); is jointly implemented with the Policy Studies Institute (PSI); and is financially supported by the United States Agency for International Development (USAID), the Department for International Development (DFID) of the government of the United Kingdom, and the European Union (EU). The research presented here was conducted as part of the CGIAR Research Program on Policies, Institutions, and Markets (PIM), which is led by IFPRI. This publication has been prepared as an output of ESSP and has not been independently peer reviewed. Any opinions expressed here belong to the author(s) and are not necessarily representative of or endorsed by IFPRI, PSI, USAID, DFID, EU, PIM, or CGIAR. 